\title{
Pulsed Doppler echocardiographic indices for assessing mitral regurgitation
}

\author{
COLETTE VEYRAT, A AMEUR, SYLVIE BAS, A LESSANA, G ABITBOL, \\ D KALMANSON
}

From the Service de Cardiologie, Fondation A de Rothschild, and the Centre Hospitalier Privé La Roseraie, Paris France

SUMmary Pulsed Doppler indices were devised in order to grade the severity of mitral regurgitation on a quantitative basis. Indices were obtained by mapping the regurgitant jet by recording abnormal systolic Doppler signals detected on a "yes/no" basis using a $3 \mathrm{MHz}$ pulsed Doppler velocimeter associated with a cross sectional real time ultrasonic scanner. Combined information from two echographic planes was used to take into account the geometrical three dimensional configuration of the jet. The following dimensions of the jet were measured: $(a)$ the length and the height in the long axis view of the left atrium (long axis regurgitant index (LARI), $0.5 \times$ length $\times$ height); $(b)$ the width at the annulus in the short axis view (short axis regurgitant index (SARI)); (c) the total regurgitant index (TRI) calculated as the product of LARI multiplied by SARI. Sixteen normal subjects and 94 patients including 46 cases of mitral regurgitation confirmed by angiography ( 32 of whom proceeded to surgery) were investigated. The diagnostic sensitivity was $91 \%$ and the specificity $94 \%$. The jet was detected in $76 \%$ of cases. Indices were correlated with independently performed angiographic grading on a three point scale. The best linear correlation was obtained for the TRI; mean values were significantly increased for each grade of severity. Correlations with invasive procedures showed an $87 \%$ success rate for the Doppler prediction of the involved regurgitant leaflet(s) and of the anatomical site of the lesion at the annulus. In addition, an abnormal diastolic signal was found in five of the eight patients with ruptured chordae and also a decreased percentage of systolic shortening of the annulus diameter in patients with mitral regurgitation compared with those without.

Doppler techniques are often criticised because until now they have generally given only qualitative information for grading the severity of lesions. This was the case in previous reports dealing with mitral regurgitation $^{1-13}$ and led us to devise indices that would provide a quantitative grading. Ideally, such indices would take into account the geometrical three dimensional configuration of the jet that can be mapped in the left atrium by Doppler detection of turbulence. We chose the most commonly found configuration, which turned out to be a more or less round shaped peg. In the present report we define these indices and analyse their reliability.

Requests for reprints to Dr Colette Veyrat, Service de Cardiologie, Fondation A de Rothschild, 25-29 rue Manin, 75940 Paris Cédex 19, France.

Accepted for publication 2 August 1983

\section{Subjects and methods}

The study population included 16 normal subjects (seven men and nine women, mean age 35 years) and 94 patients ( 43 men and 51 women, mean age 37 years) in whom the presence of mitral regurgitation was confirmed or excluded by selective left ventricular cineangiograms performed within a week of the Doppler examination.

Diagnoses included acquired valvular lesions (mitral in 65 and aortic in 11), congenital heart diseases (atrial septal defects in seven, persistent ductus arteriosus in two, coarctation of the aorta in one), primary pulmonary hypertension in two, coronary heart disease (four), cardiomyopathies (four), and valve prostheses (seven). Some patients had more than one diagnosis. Fifty five patients were in sinus rhythm and 39 in atrial fibrillation. 
DIAGNOSIS OF MITRAL REGURGITATION

The diagnosis of mitral regurgitation relied on angiographic data. Selective left ventricular cineangiography was performed in all patients using a $30^{\circ}$ right anterior oblique projection with injection of $40-50 \mathrm{ml}$ of Renografin. Mitral regurgitation was evident in 44 patients with a total of 46 cases, two patients showing recurrent regurgitation.

The aetiology was rheumatic in 27 patients, nine with secondary mitral valve prolapse (seven anterior associated with posterior leaflet retraction, annular dilatation, and also ruptured chordae in four cases, and two of both leaflets with a cleft in one). There was also primary mitral valve prolapse in 10 , affecting the posterior (8), the anterior (1), and both leaflets (1), with three cases of ruptured chordae. There were three cases of cardiomyopathy, two of endocarditis, two of prosthetic leaks, one congenital case of anterior leaflet prolapse and chordae rupture, and one of cleft of the anterior leaflet of undetermined origin. The diagnosis was further confirmed at the time of operation in 32 patients.

\section{CLASSIFICATION OF MITRAL REGURGITATION}

The severity of the regurgitation was assessed from qualitative criteria using a three point grading scale ${ }^{14}$ : grade I (mild)-minimum jet of dye cleared at next diastole (13 lesions); grade II (moderate)-jet of dye more slowly cleared from the left atrium with progressive atrial opacification remaining fainter than that of the left ventricle (12 lesions); and grade III (severe)-rapid or immediate left atrial opacification at least equal to that of the left ventricle (21 lesions).

\section{DOPPLER EXAMINATION}

Apparatus

A $3 \mathrm{MHz}$ ATL851 (Squibb Medical Systems, Bellevue, Washington, USA) mechanical real time scanner was used, providing a $90^{\circ}$ sector and single gate steerable pulsed Doppler capability. The Doppler output could be presented as an audible signal, a time interval histogram, an analogue flow velocity trace, and a real time frequency spectrum by means of a fast Fourier transform analyser (Unigon Industries, Mount Vernon, New York, USA). The principles and characteristics of the instruments used have been described elsewhere. ${ }^{11} 15-17$

\section{Criteria for diagnosis}

The main criterion for a pulsed Doppler diagnosis of mitral regurgitation at the mitral valve annulus was the presence of a Doppler signal in systole. This was established on a "yes/no" basis, a signal being considered to be present if there was a "rough" audio signal, the frequency spectral recording was at least twice the width of the baseline, and the duration of the disturbance was at least $0.1 \mathrm{~s}$, ignoring brief transients due to valve movements. When the flow signals had a net velocity deflexion from the baseline in systole the diagnosis was further established by the presence of reverse flow, whether or not the main criterion was satisfied.

\section{Echocardiographic approaches}

The investigation used a sequential combination of two scan planes:

Parasternal long axis view (Fig. 1a)-After a satisfactory image of the left cavities had been obtained the entire left atrial area from the annulus towards the
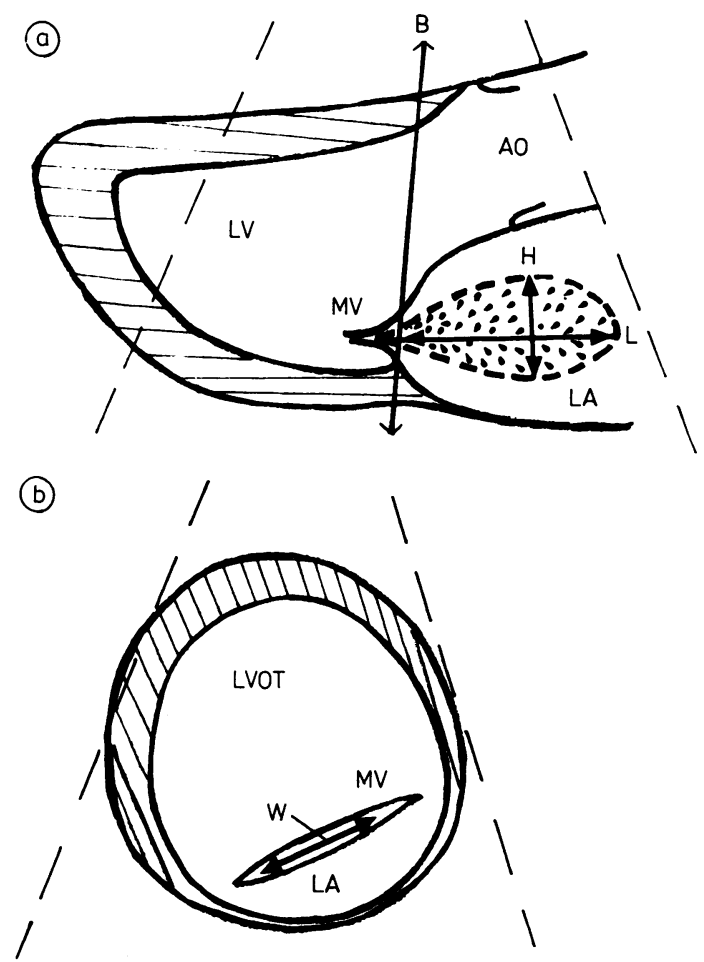

Fig. 1 Schematic representation of the procedure used for calculating the mitral regurgitant indices. (a) Long axis view: the left atrium is first mapped with the Doppler sample gate in long axis to detect the regurgitant jet (dotted area), to measure its length and height, and to calculate the long axis regurgitant index $(L A R I=1 / 2$ length $\times$ height $)$. (b) Short axis view: the mitral annulus is examined in short axis view, according to the plane $B$ represented in $(a)$; the annulus is mapped with the Doppler gate to detect the site of the regurgitation and to measure its annular width, which represents the short axis regurgitant index (SARI). The total regurgitant index (TRI) is equal to the product of $L A R I \times$ $S A R I$. $L V$, left ventricle; $M V$, mitral valve; $H$, height of regurgitant jet; $L A$, left atrium; $L$, length of regurgitant jet; $A O$, aorta; $L V O T$, left ventricular outflow tract; $W$, width of regurgitant jet. 
origin of the pulmonary vein was explored with the Doppler sample volume from the anterior to the posterior wall to search for any abnormal Doppler signals. When abnormal signals were detected the direction and atrial extension of the jet were noted. The presence of any minor disturbances around the jet were also noted. Once the limits of the jet had been determined a transparent plastic sheet was placed over the video display screen and used to measure its size. Because of the rather triangular shape of the jet, the product $(0.5 \times$ length $\times$ height $)$ was calculated and called the long axis regurgitant index (LARI).

Parasternal short axis view (Fig. 1b)-Using a transverse approach to the mitral valve annulus the entire area was explored for abnormal Doppler signals. When a disturbance was detected, its site (central, internal, or external, or all three) was noted and its width (measured in centimetres using a transparent plastic overlay) was recorded as the short axis regurgitant index (SARI). The product $(0.5 \times$ length $\times$ height) $\times$ width was then calculated to give the total regurgitant index (TRI).

During the real time examination two echocardiographic indices ${ }^{1819}$ were also measured to estimate the percentage systolic decrease of the mitral annulus diameter: the systolic diameter and the maximum anteroposterior diastolic diameters. The measurements were made using a transparent plastic overlay on the frozen image frame (Fig. 2). The percentage systolic decrease was calculated as the ratio of these two indices:

$$
\frac{\text { diastolic }- \text { systolic diameter }}{\text { diastolic diameter }}
$$

Three sequences of systolic beats were analysed and averaged to determine each index. All the patients were examined by two observers; no evidence of interobserver disagreement was found in a test of 30 random reviews of videotapes. Measured indices were corrected for body surface area. The ultrasound findings were analysed without knowledge of the results of the invasive procedures, which were performed by separate teams. A statistical analysis of the results was made using a Hewlett Packard 4815. Values are expressed as means \pm 1 standard deviation. The significance of the differences between the mean values was assessed using Student's $t$ test $(t$ and $\mathrm{p}$ ). Correlation coefficients were determined for values of the total regurgitant index correlated with the angiographic grading.

\section{Results}

\section{NORMAL SUBJECTS}

Fig. 3 shows a typical long axis view. No anomaly was detected in systole, either at the annulus or in the left atrium. In atrial recordings forward laminar systolic flow with a smooth sounding Doppler signal was often
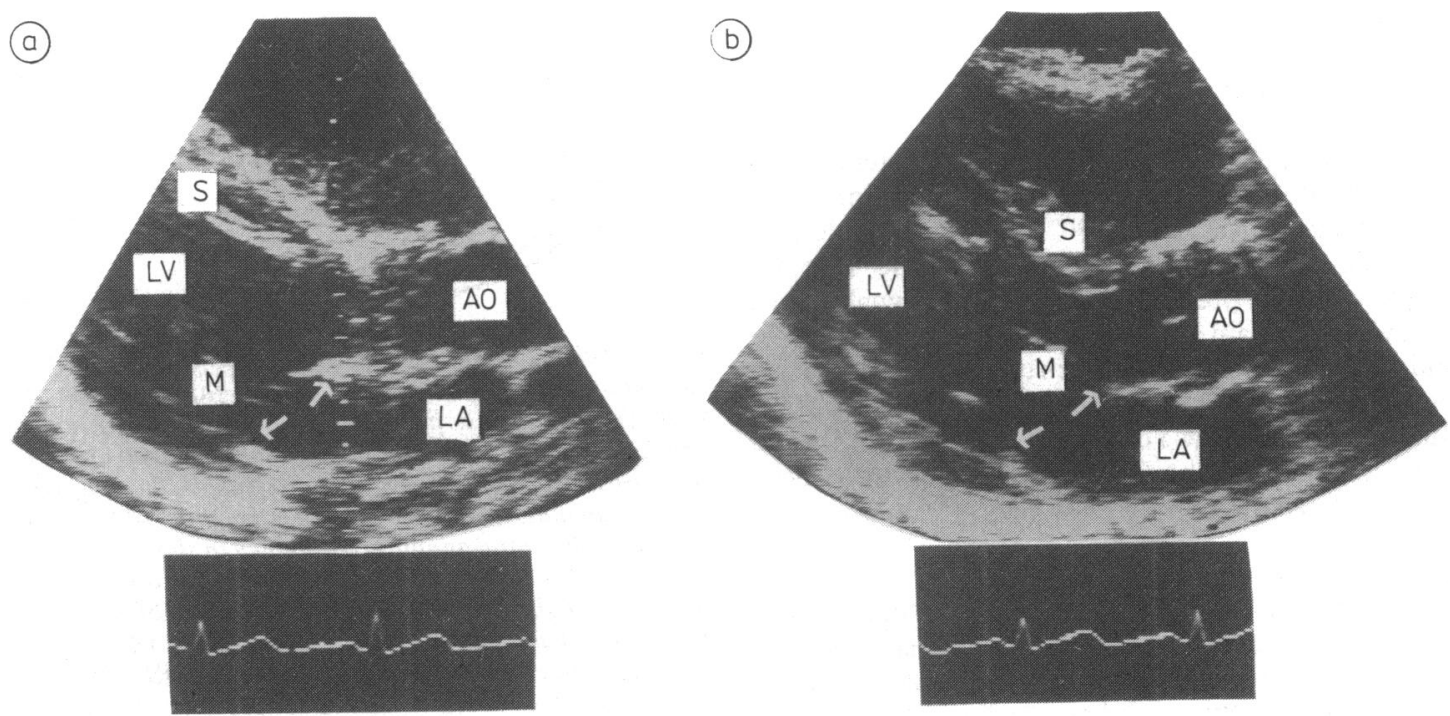

Fig. 2 Measurement of the mitral valve annulus diameter in the long axis view at (a) systole and (b) diastole (as shown on the triggered electrocardiogram). The systolic decrease of the diameter is expressed as the percentage change from the diastolic diameter. $S$, interventricular septum; $M$, mitral orifice; for other abbreviations, see Fig. 1. 


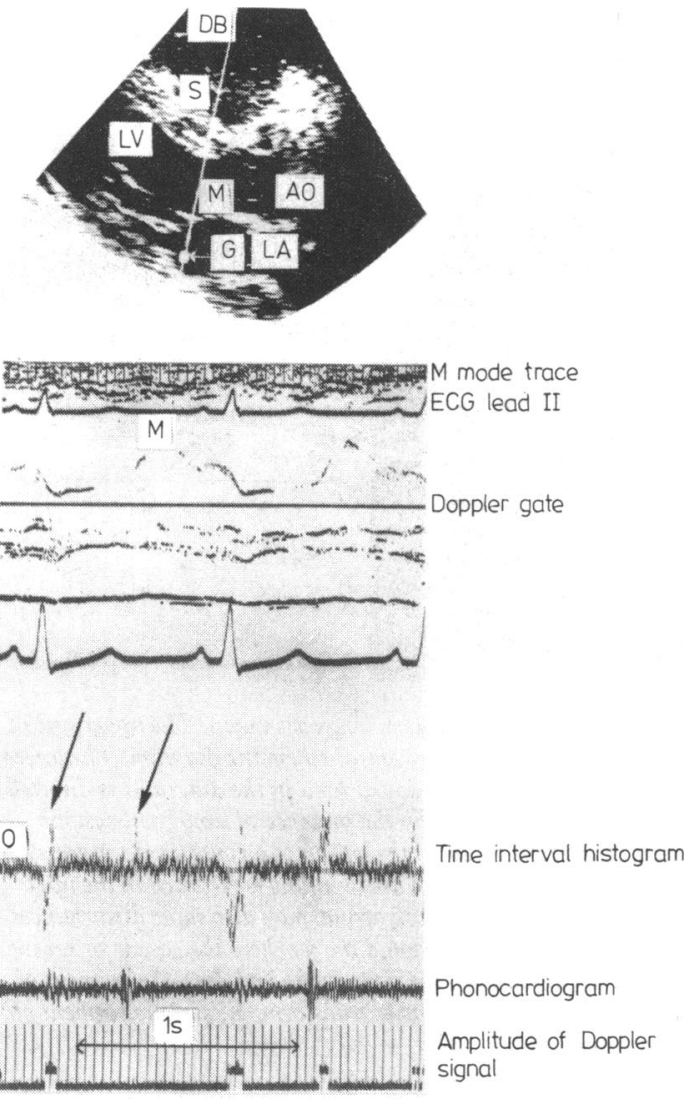

Fig. 3 Doppler recording at the mitral valve in normal subjects and in patients without mitral regurgitation. Top: the long axis scan plane is shown with the Doppler beam $(D B)$ position (white line) and the Doppler sample gate $(G$, white spot) located at the mitral orifice towards the atrial side. Below: the frequency spectrum is displayed just below the centre as a thin line of clustered dots, only interrupted by deflexions of short duration (arrows) related to the closing and opening of the mitral valve. For abbreviations, see Fig. $1 ; O$, baseline of frequency spectral display.

noted. Fig. 4 shows the normal values for the percentage systolic decrease of the mitral annulus diameter.

\section{PATIENTS WITH MITRAL REGURGITATION}

Fig. 5 shows typical long axis scans. The Table shows the results. The total number of cases of mitral regurgitation (46) included the 44 patients with regurgitation confirmed by angiography and the two with recurrent regurgitation. The angiographic grading scheme followed the classification previously described. The sensitivity of the Doppler examination was $91 \%$ and its specificity $94 \%$.

Left atrial detection of regurgitant jet

As indicated in the Table regurgitant jets were

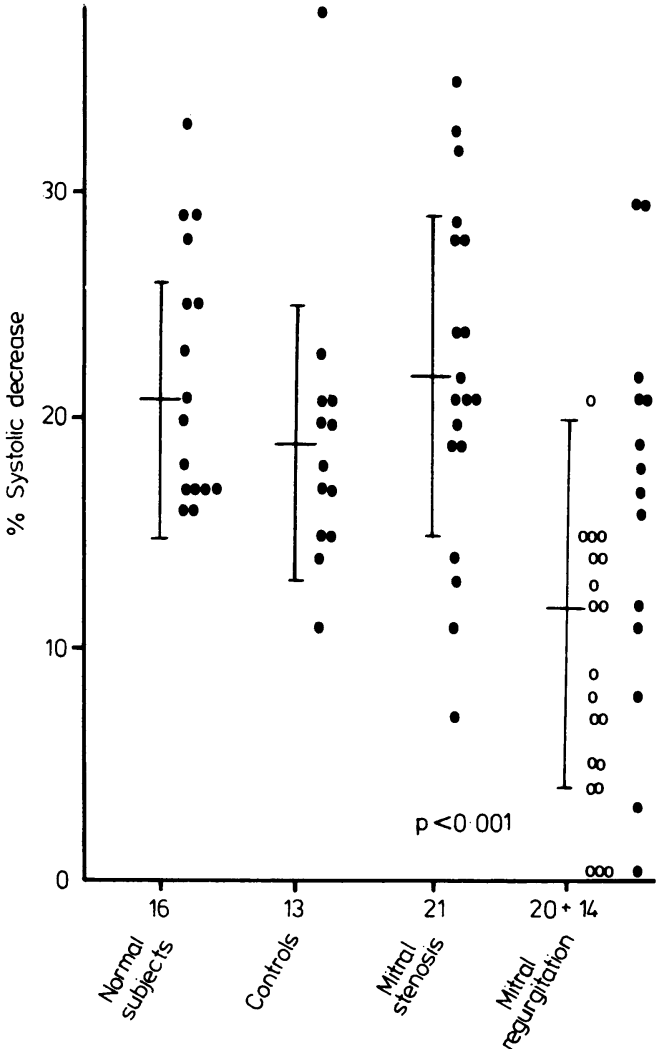

Fig. 4 Results of measurements of percentage systolic decrease of mitral valve annulus diameter. The values are significantly lower in the patients with pure mitral regurgitation (O) and in those with dilated annulus confurmed at surgery (O). Bars represent means $\pm S D(9 \pm 5 \%$ for patients with dilated annulus and $16 \pm 8 \%$ for patients without annular dilatation $(p<0.01))$.

detected in $76 \%$ of cases. The sound of the regurgitant jet Doppler signal was particularly harsh when it touched the left atrial structures towards which it was directed. The jet was surrounded by left atrial disturbances having less rough sounds and more laminar frequency spectra in 21 patients with moderate or severe lesions. In five of these, with free regurgitation, disturbances were found throughout the whole atrium.

\section{Assessment of severity of mitral regurgitation}

As indicated in Fig. 6, calculation of the total regurgitant index gave an accurate evaluation in 31 out of $35(89 \%)$ patients. The mean values of LARI, SARI, and TRI all increased with increasing grade of severity, but only TRI gave significant differentiation between the grades. Correction for body surface area did not improve the significance. The correlation 


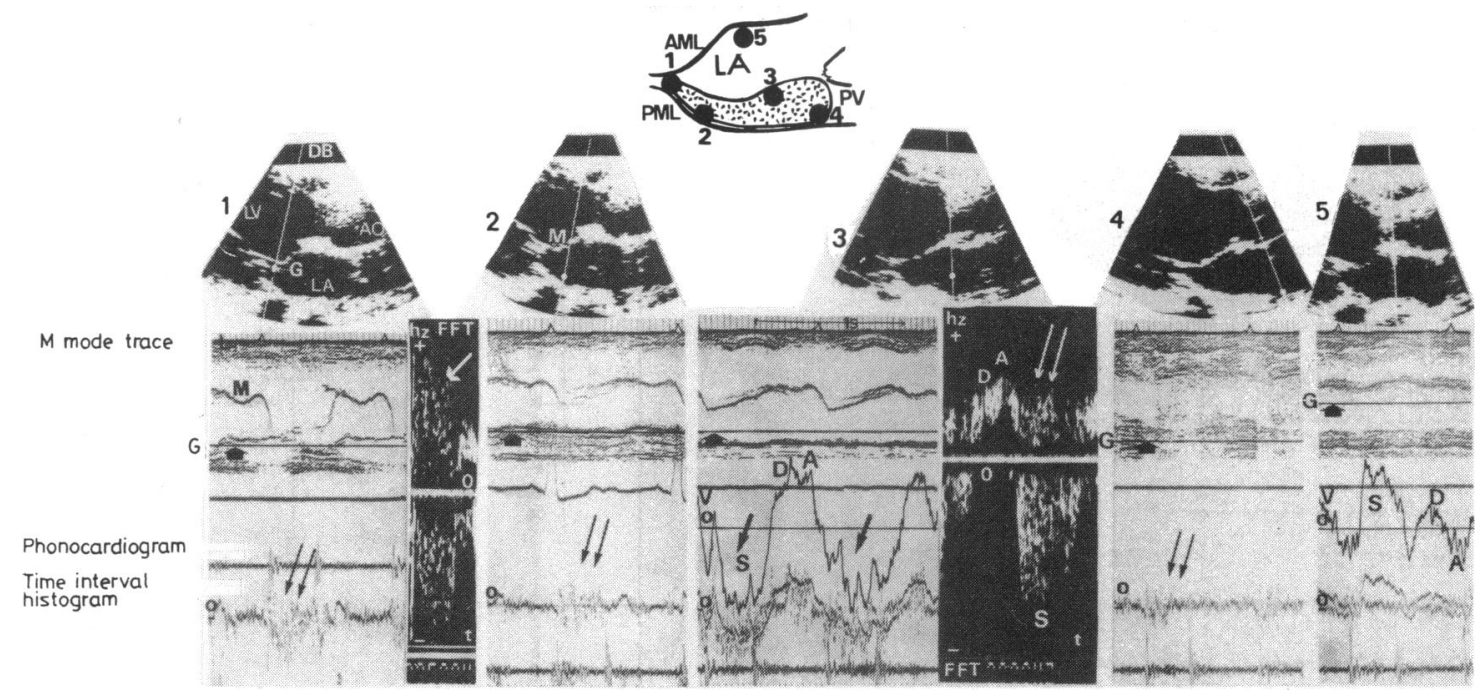

Fig. 5 Mitral regurgitation: example of Doppler study of the atrial spread of the regurgitant jet in long axis views. The upper row of scans shows various positions $(1,2,3,4$, and 5) of the Doppler sample gate as indicated in the central schematic diagram. The lower row shows the corresponding Doppler recordings. In positions 1, 2, and 4 the regurgitant jet (dotted area in the diagram) is directed inferiorly towards the left atrial posterior wall and reaches the pulmonary vein, as confirmed by the presence of abnormal systolic spectral broadening (black and white arrows). In position 3 the gate located in the full stream of the jet shows a conspicuous negative $S$ wave (thick arrows) associated with a spectral broadening (white arrows). In position 5, normal atrial inflow is recorded in the upper part of the left atrium near the posterior aortic wall. In some cases of severe regurgitation the entire atrium may also show disturbances with smoother sounds consisting of a negative systolic wave with a pseudolaminar spectrum around the jet (here the case is of severe regurgitation (TRI 1248) related to an anterior mitral valve prolapse). For abbreviations, see Fig. 1; $A$, end diastolic segment of mitral flow velocity trace; $t$, time axis; FFT, real time frequency spectral analysis by fast Fourier transform; $S$, systolic segment of mitral flow velocity trace; $D$, early diastolic segment of mitral flow velocity trace.

coefficient between TRI and angiographic grading was $r=0.70(p<0.01)$ for the linear model and $r=0.88$ $(p<0.001)$ for the exponential model (because of the high values of TRI corresponding to severe disease).

Direction and annular site of the jet: correlation with invasive procedures

In the long axis view, the Doppler findings could be correlated with invasive procedures in only 31 cases. Doppler detected the jet in the central position in 16 cases. Angiography confirmed this in 13 cases. In 10 of these, a central gap with associated stenosis (8) and an isolated annular dilatation (2) were detected at surgery. Doppler showed the jet to be directed anteriorly towards the posterior aortic wall in eight cases, suggesting a posterior valve prolapse. Angiography showed that the jet had a counter clockwise rotation in five cases. At surgery, a posterior valve prolapse was found in all five and also in a further case with associated minor anterior prolapse.

Doppler detected the jet to be directed inferiorly and posteriorly towards the posterior atrial wall in 11 cases, with or without a more central spreading, and predicted an anterior valve prolapse. Angiography showed that the jet had a clockwise rotation which was related to an anterior valve prolapse in seven cases and to a cleft anterior leaflet in one as confirmed at surgery. Five of the surgically confirmed cases had smoother sounding Doppler signals, and in these the

Table Pulsed Doppler diagnosis and the detection of the jet in mitral regurgitation. Figures are numbers of cases

\begin{tabular}{lllll}
\hline $\begin{array}{l}\text { Diagnosis } \\
\text { and grading } \\
\text { of severity }\end{array}$ & Angiography & \multicolumn{3}{l}{ Doppler technique } \\
\cline { 3 - 5 } & & $\begin{array}{l}\text { Positive } \\
\text { diagnosis }\end{array}$ & $\begin{array}{l}\text { Negative } \\
\text { diagnosis }\end{array}$ & $\begin{array}{l}\text { Detection } \\
\text { of jet }\end{array}$ \\
\hline $\begin{array}{l}\text { Positive } \\
\text { diagnosis }\end{array}$ & $46^{\star}$ & 42 & $4^{\star}+$ & 35 \\
$\begin{array}{l}\text { Negative } \\
\text { diagnosis }\end{array}$ & 50 & 3 & 47 & \\
$\begin{array}{l}\text { Grade I } \\
\text { Grade II }\end{array}$ & 13 & 10 & & 8 \\
Grade III & 21 & 11 & & 98 \\
\hline
\end{tabular}

*Including two with recurrent regurgitation.

†Including one technically unsatisfactory examination of a patient with angiographic grade Il regurgitation. 


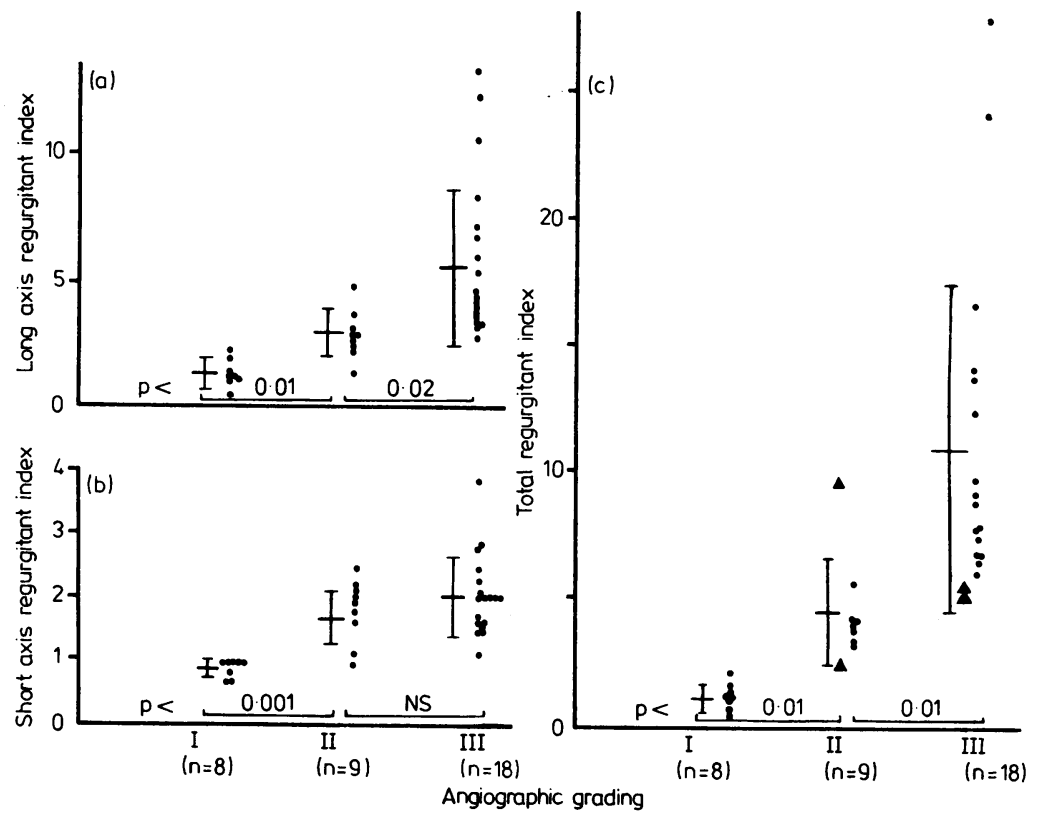

Fig. 6 Values of the indices used for assessing mitral regurgitation. The data are expressed as the mean $\pm 1 S D$ for each grade, with individual values shown as solid circles (O): (a) values of LARI; (b) values of SARI; (c) values of TRI (discrepant values are shown as ( $\Delta)$ ). The TRI provides the most significant differentiation between each grade of severity. The linear correlation coefficient is at 0.70; the coefficient increases to 0.88 for the exponential model because of large values found for free regurgitation.

Fig. 7 Doppler detection of the site and width of the regurgitation in the short axis view and of ruptured chordae. The upper row of scans shows the mitral orifice with different positions 1, 2, and 3 of the Doppler sample gate. The lower row shows the corresponding Doppler recordings. Abnormal systolic spectral broadening (oblique arrows) is shown all along the width of the annulus ( $1,2,3 a)$ with a negative systolic backflow wave $(S)$ at the extermal part (3a). In positions 1 and 2, the diastolic inflow, although poorly recorded because of the undesirable angle, is undisturbed; in $3 a$, disturbed diastolic inflow is present $(D$, vertical arrow). In $3 b$, the gate has been moved towards the ventricular chamber (left ventricle posterior wall at the bottom of the $M$ mode echo trace): the TIH is normal in systole but conspicuously disturbed during most of diastole. In this case of severe regurgitation (TRI 16.74) due to anterior mitral valve prolapse, surgery showed chordae rupture at the external commissure. For abbreviations, see Fig. 1; $S$, negative systolic reverse flow wave; $D$, diastolic inflow. 
prolapse was secondary to a rheumatic process affecting chordae elongation, dilated annulus, and retracted posterior leaflet.

Four discrepancies were noted (corresponding to a success rate of $87 \%$ ). One anterior valve prolapse detected at surgery was missed by Doppler, which showed only a central jet. Three predictions of anterior valve prolapse by Doppler were found to be erroneous at surgery. These four patients had multiple lesions with annular dilatation; three had a retracted posterior leaflet and one an associated atrial septal defect.

In the short axis view, typical examples of which are shown in Fig. 7, the annular site was compared with the surgical findings in 13 patients with valve prolapse. The site was central in nine patients, external in one, and internal in another; in all these the Doppler findings were correct. There were two discrepancies, corresponding to a success rate of $85 \%$.

\section{Ruptured chordae}

No difference was seen on the Doppler recordings in systole in the eight cases of ruptured chordae. In five of these, prolonged diastolic disturbances with a very harsh Doppler sound similar to that heard in systole were found in the inflow tract facing the annular site of the regurgitant lesion.

\section{Systolic decrease in annulus diameter}

Fig. 4 shows the significantly decreased percentage of systolic shortening in patients with mitral regurgitation (12 \pm 8$)$, compared with that in the normal subjects and patients in the control group. The percentages were significantly lower in those with annular dilatation $(9 \pm 5)$ than in those without $(16 \pm 8)$ $(\mathrm{p}<0.01)$.

\section{Discussion}

It is now accepted that cross sectional real time echography has improved the visualisation of the mitral valve structures. ${ }^{20} 21$ Doppler ultrasound is necessary, however, to diagnose mitral regurgitation noninvasively by detecting reverse flow through the mitral valve annulus.

The fundamental, theoretical, and technological limitations of the pulsed Doppler method are well known. ${ }^{1522}$ The most important of these are the Nyquist limit in recording high velocities at any given depth, the noise in the receiver, and the gain dependence of the output display. Ways of minimising the effects of some of these problems have been proposed, ${ }^{11} 2324$ but difficulties still remain. An important advantage of the present method is that it is relatively insensitive to these limitations, because it depends on a "yes/no" decision concerning the presence or absence of a Doppler signal and not on the absolute velocities of the jet, as taken in its strict sense of fluid dynamics.

\section{VARIOUS DOPPLER ECHOGRAPHIC APPROACHES}

The apical approach initially proposed when using one dimensional echo Doppler ${ }^{2}$ has the advantage that the directions of the flow and the ultrasound are parallel. Diagnosis relied on the detection of systolic reverse flow and the assessment of severity on the spatial spread of the anomaly at the annulus. We agree with other investigators ${ }^{6}$ that it remains the best procedure when using a one dimensional Doppler system.

The cross sectional approach that we now recommend provides unique information about the atrial spread of the jet (from the long axis view) and about its annular extent (from the short axis view). Despite the undesirable angle between the directions of the flow and of the ultrasound, the method has two clear advantages. Firstly, the Doppler sample is closer to the ultrasonic transducer and, secondly, adequate information is obtained concerning the direction of the regurgitant jet.

\section{VALIDITY OF THE NEW PROCEDURE}

The small number of failures with the new procedure were mainly related to two factors: non-axial direction of the jet in cases of mild regurgitation and a poor signal to noise ratio. One of the three false positive diagnoses was in a patient with an atrial septal defect. This failure raises the problem of the possibly ambiguous origin of flow disturbances, since a transient right to left shunt is known to occur in systole in such patients and could be misleading. The two other false positive diagnoses remain unexplained and raise the question of a possibly greater sensitivity of Doppler compared with angiography in cases of minimal regurgitation.

Cross sectional Doppler studies can provide a straightforward but rough estimate of the degree of regurgitation in terms of the atrial extent of the disturbed flow in the long axis plane. Accurate grading, however, demands a more objective evaluation. Fig. 5 shows that the best differentiation between grades is provided by an index obtained from measurements performed in two planes. Clearly, the total regurgitant index does not really represent the true three dimensional complexity of the regurgitant jet. Some errors, for instance, might be expected when the long axis view does not transect the plane of maximal spread of the regurgitation. Whatever the true physical significance of the index may be, for clinical purposes it satisfies the needs of the physicians and the surgeons. 


\section{PATHOPHYSIOLOGICAL IMPLICATIONS OF THE} DOPPLER FINDINGS

\section{Mechanism of regurgitation}

The mapping procedure described here gives a better understanding of the underlying mechanism of mitral valve regurgitation. The ability to map the left atrium, in long axis only, was first reported by Miyatake et al. ${ }^{9}$ In two previous studies ${ }^{11} 12$ we modified this technique by adding short axis information in order to detect which part of the annulus was affected. We also correlated the Doppler findings with angiographic data and proposed the following pathophysiological classification for the three main directions of regurgitant jets: $(a)$ those directed to the anterior atrial wall were related to posterior valve prolapse; $(b)$ those directed to the posterior atrial wall were related to anterior valve prolapse; and $(c)$ those directed to the mid-portion of the atrium were mostly due to mixed mitral lesions.

We also noted that prolapse of both leaflets resulted in either a central jet or a jet corresponding to the predominant prolapsed leaflet. This and a recent study ${ }^{10}$ confirm these preliminary findings, which are also in agreement with angiographic descriptions of jets. ${ }^{25}$

Some comments are required about jets observed in rheumatic lesions. The central direction of the jet, generally seen in combined lesions, does not uniformly apply to all pure or predominant rheumatic regurgitations, in which a wide range of mechanisms is concerned, frequently including an anterior valve prolapse with various chordal lesions. Two lesions are often involved in the rheumatic process. These are a retracted posterior leaflet and a dilated annulus which may generate a jet somehow mimicking that due to an anterior valve prolapse, as was observed in some discrepant findings. Combined lesions may also generate different jets in a given patient. For example, a jet may be directed to the atrial mid-portion at the centre of the annulus with another jet directed to the posterior atrial wall at a commissure if it is the site of a localised anterior prolapse.

The last comment about the mechanism of regurgitation concerns the difficulties sometimes encountered in correlations with the results of invasive procedures. Whereas Doppler detection of the jet remains unaffected by the severity of the regurgitation, recognition of a jet may be difficult at angiography in free regurgitation. As for surgery, it easily recognises the primary anatomical lesions but may fail to single out the determinant regurgitant factor in cases of multiple lesions. Above all, surgery may fail to detect a secondary dysfunction of an otherwise anatomically normal structure, coupled with diseased components of the mitral apparatus.

\section{Ruptured chordae}

Although it is too early to make a definite statement, the unusually rough sound of the Doppler signals from flow in diastole might be suggestive of ruptured chordae. The sound is different from that heard in organic stenosis, and the duration of the disturbance exceeds that seen in functional inflow murmur. The study of the specificity of this finding requires the investigation of cases with pronounced chordae elongation without rupture.

\section{Echocardiographic examination of the annulus}

Despite the errors that may possibly occur when using long axis information, ${ }^{26}$ the finding of a notable decrease of systolic shortening in mitral valve annulus diameter in patients with annular dilatation has a practical role when the desirability of further reconstructive surgery is considered.

\section{LIMITATIONS OF THE NEW PROCEDURE}

Among the technological limitations, that most requiring attention is the poor signal to noise ratio of the Doppler system. This may result in a false negative diagnosis when there is pronounced atrial enlargement and low cardiac output. Despite this, technically unsatisfactory examinations are exceptional. Positive diagnoses were always obtained in patients with prostheses and when disturbances were found near the posterior atrial wall. In no case was it possible, however, to map the jet from an annular leak, and therefore this led to failure in identifying this mechanism. In addition to the possibility of missing a jet, a mechanism of regurgitation may not be detected when there are several associated factors. Clinically silent incompetent valves ${ }^{27}$ were never encountered, although theoretically these could result in a limitation to the mapping of disturbances in the atrium.

The work was partly supported by grants from CNAMTS and the ARNTIC Research Association. We thank Professor P N T Wells for his kind assistance.

\section{References}

1 Johnson SL, Baker DW, Lute RA, Dodge HT. Doppler echocardiography. The localization of cardiac murmurs. Circulation 1973; 48: 810-22.

2 Kalmanson D, Veyrat C, Bouchareine F, Degroote A. Non-invasive recording of mitral valve flow velocity patterns using pulsed Doppler echocardiography. Br Heart f 1977; 39: 517-28.

3 Stevenson JG, Kawabori I, Guntheroth WG. Differentiation of ventricular septal dejfects from mitral regurgitation by pulsed Doppler echocardiography. Circulation, 1977, 56: 14-8. 
4 Diebold B, Theroux P, Bourassa MG, et al. Noninvasive pulsed Doppler study of mitral stenosis and mitral regurgitation: preliminary study. $B r$ Heart $\mathcal{F} 1979$; 42: 168-75.

5 Abbasi AS, Allen MW, DeCristofaro D, Ungar I. Detection and estimation of the degree of mitral regurgitation by range-gated pulsed Doppler echocardiography. Circulation 1980; 61: 143-7.

6 Quinones MA, Young JB, Waggoner AD, Ostojic MC, Ribeiro LG, Miller RR. Assessment of pulsed Doppler echocardiography in detection and quantification of aortic and mitral regurgitation. Br Heart f 1980; 44: 612-20.

7 Blanchard D, Diebold B, Peronneau P, et al. Noninvasive diagnosis of mitral regurgitation by Doppler echocardiography. $\mathrm{Br}$ Heart $\mathcal{f}$ 1981; 45: 589-93.

8 Kalmanson D, Veyrat C, Abitbol G. Two-dimensional echo Doppler velocimetry in mitral and tricuspid valve disease. In: Kurjak A, ed. Recent advances in ultrasound diagnosis. Amsterdam: Excerpta Medica, 1979: 335-48.

9 Miyatake K, Kinoshita N, Nagata S, et al. Intracardiac flow pattern in mitral regurgitation studied with combined use of the ultrasonic pulsed Doppler technique and cross-sectional echocardiography. Am $\mathcal{F}$ Cardiol 1980; 45: 155-62.

10 Miyatake K, Nimura Y, Sakakibara H, et al. Localisation and direction of mitral regurgitant flow in mitral orifice studied with combined use of ultrasonic pulsed Doppler technique and two-dimensional echocardiography. Br Heart f 1982; 48: 449-58.

11 Kalmanson D, Veyrat C, Abitbol G, Farion M. Doppler echocardiography and valvular regurgitation, with special emphasis on mitral insufficiency. In: Rijsterborgh $\mathrm{H}$, ed. Echocardiology. The Hague: Nijhoff, 1981: 279-90.

12 Kalmanson D, Veyrat C, Abitbol G, Manin JP. Contribution du scanner-Doppler pulsé au diagnostic des régurgitations du prolapsus mitral. Rapport pre'liminaire. Ann Cardiol Angeiol (Paris) 1981; 30: 25-35.

13 Veyrat C, Villemot JP, Manin JP, Cabrol C, Kalmanson D. Anatomic and functional evaluation of pure and associated mitral stenoses using the echo-Doppler scanner technique. Ultrasound Med Biol 1983; 9: 1-17.

14 Carrillo Kabana J, Calderón Montero J, Lopez Sendón J, Fuertes Garcia A, Pey-Illera J. Valoración cuantitativa y cualitativa de las insuficiencias mitral y aórtica. Estudio comparativo. Rev Esp Cardiol 1976; 29: 227-35.

15 Baker DW, Rubenstein S, Lorch GS. Pulsed Doppler echocardiography. Principles and applications. $A m \mathcal{F}$
Med 1977; 63: 69-80.

16 Macpherson PC, Meldrum SJ, Tunstall-Pedoe DS. Angioscan: a spectrum analyser for use with ultrasonic Doppler velocimeters. F Med Eng Technol 1981; 5: 84-5.

17 Veyrat C, Kalmanson D, Farion M, Guichard J, Sainte-Beuve D, Abitbol G. Combined pulsed-Doppler echocardiography for the investigation of valvular heart diseases: one-dimensional versus two-dimensional approach. In: Rijsterborgh H, ed. Echocardiology. The Hague: Nihhoff, 1981: 291-8.

18 Kuwako K, Umeda T, Machii K. Determination of the site of the prolapse and regurgitation of the mitral valve by real-time two-dimensional echocardiography with contrast technique. $\mathcal{f}$ Cardiography 1980; 10: 89-99.

19 Chandraratna PAN, Aronow WS, Murdock K. Crosssectional echocardiographic study of the mitral ring in the normal versus the dilated left ventricle [Abstract]. Circulation 1978; 58, suppl II: 42.

20 Wann LS, Feigenbaum H, Weyman AE, Dillon JC. Cross-sectional echocardiographic detection of rheumatic mitral regurgitation. Am $\mathcal{F}$ Cardiol 1978; 41: 1258-63.

21 Popp RL. Reliability of M mode and cross-sectional echocardiographic criteria for the diagnosis of mitral valve disorders. In: Lancee CT, ed. Echocardiology. The Hague: Nijhoff, 1979: 203-12.

22 Lunt MJ. Accuracy and limitations of the ultrasonic Doppler blood velocimeter and zero crossing detector. Ultrasound Med Biol 1975; 2: 1-10.

23 Tunstall Pedoe DS, Macpherson PC, Meldrum SJ. Absolute intracardiac blood velocities measured with continuous wave Doppler and a new real-time spectral display. In: Lancee CT, ed. Echocardiology. The Hague: Nijhoff, 1979: 77-80.

24 Miller L, Bommer WJ, Mason DT, Demaria A. Quantitative Doppler flow estimators: improved characterization and separation of normal from abnormal flow [Abstract]. Am f Cardiol 1981; 47: 461.

25 Gavelle $\mathrm{P}$, Tricot JL, Guermonprez JL. La cinéangiographie de l'insuffisance mitrale. Gazette des Hopitaux 1973 ; 145(4), 153-66.

26 Ormiston JA, Shah PM, Tei C, Wong M. Size and motion of the mitral valve annulus in man. I. A twodimensional echocardiographic method and findings in normal subjects. Circulation 1981; 64: 113-20.

27 Schrire V, Vogelpoel L, Nellen M, Swanepoel A, Beck W. Silent mitral incompetence. Am Heart $\mathcal{F}$ 1961; 61: 723-32. 